\title{
Empagliflozin Improves Liver Steatosis and Fibrosis in Patients with Non-Alcoholic Fatty Liver Disease and Type 2 Diabetes: A Randomized, Double-Blind, Placebo-Controlled Clinical Trial
}

\author{
Haleh Chehrehgosha · Masoud Reza Sohrabi · Faramarz Ismail-Beigi • \\ Mojtaba Malek · Mohammad Reza Babaei · Farhad Zamani · Hossein Ajdarkosh • \\ Mahmood Khoonsari · Afshin Eshghi Fallah · Mohammad E. Khamseh (D
}

Received: December 9, 2020 / Accepted: January 23, 2021 / Published online: February 14, 2021

(c) The Author(s) 2021

\section{ABSTRACT}

Introduction: To evaluate the efficacy of empagliflozin compared to pioglitazone in patients with non-alcoholic fatty liver disease (NAFLD) and type 2 diabetes (T2DM).

Supplementary Information The online version contains supplementary material available at https:// doi.org/10.1007/s13300-021-01011-3.

H. Chehrehgosha - A. E. Fallah · M. E. Khamseh ( $₫)$ Endocrine Research Center, Institute of Endocrinology and Metabolism, Iran University of Medical Sciences (IUMS), Tehran, Iran

e-mail: khamseh.m@iums.ac.ir

M. Malek

Research Center for Prevention of Cardiovascular Disease, Institute of Endocrinology and Metabolism, Iran University of Medical Sciences (IUMS), Tehran, Iran

M. Reza Babaei

Department of Interventional Radiology, Firouzgar Hospital, Iran University of Medical Sciences (IUMS), Tehran, Iran

M. R. Sohrabi · F. Zamani · H. Ajdarkosh ·

M. Khoonsari

Gastrointestinal and Liver Disease Research Center, Iran University of Medical Sciences (IUMS), Tehran, Iran

F. Ismail-Beigi

Department of Medicine, Case Western Reserve University, University Hospitals Cleveland Medical Center, Cleveland, $\mathrm{OH} 44106$, USA
Methods: In this prospective randomized, double-blind, placebo-controlled trial, we assigned 106 patients with NAFLD and T2DM to receive empagliflozin $10 \mathrm{mg}(n=35)$, pioglitazone $30 \mathrm{mg}(n=34)$, or placebo $(n=37)$ for 24 weeks. Liver fat content and liver stiffness were measured using fibroscans. Body composition assessment was performed by dual-energy x-ray absorptiometry (DEXA) scans. The primary end point was change from baseline in liver steatosis, using the controlled attenuation parameter (CAP) score.

Results: A borderline significant decrease in CAP score was observed with empagliflozin compared to placebo, mean difference: $-29.6 \mathrm{~dB} / \mathrm{m} \quad(-39.5$ to -19.6$)$ versus $-16.4 \mathrm{~dB} / \mathrm{m}$ ( -25.0 to -7.8$)$, respectively; $p=0.05$. Using multivariate analysis, we observed a significant reduction in the placebocorrected change in liver stiffness measurement (LSM) with empagliflozin compared to pioglitazone: $-0.77 \mathrm{kPa}(-1.45,-0.09), p=0.02$, versus $0.01 \mathrm{kPa}(95 \% \mathrm{CI}-0.70,0.71, p=0.98)$, $p$ for comparison $=0.03$. Changes in serum aspartate aminotransferase (AST) and alanine aminotransferase (ALT), fasting insulin, homeostatic model assessment for insulin resistance (HOMA-IR), HOMA2-IR, fibrosis-4 index (FIB4 index), NAFLD fibrosis score, aspartate aminotransferase to platelet ratio index (APRI), android/gynecoid ratio (A/G ratio), and skeletal muscle index (SMI) were comparable between the two treatment groups, while significant 
reductions of the body weight and visceral fat area were observed only in the empagliflozin group ( $p<0.001$ and $p=0.01$, respectively) and both were increased in the placebo and pioglitazone groups. There were no serious adverse events in either group.

Conclusion: Treatment for 24 weeks with empagliflozin, in contrast to pioglitazone, was associated with improvement of liver steatosis and fibrosis in patients with NAFLD and T2DM. In addition, body weight and abdominal fat area were decreased in the empagliflozin group.

Trial Registration: Iranian Registry of Clinical Trials (IRCT), IRCT20190122042450N3.

Keywords: Body composition; Empagliflozin; Fibroscan; Liver fibrosis; Non-alcoholic fatty liver disease (NAFLD); Nonalcoholic steatohepatitis (NASH); Pioglitazone; Steatosis

\section{Key Summary Points}

The prevalence of non-alcoholic fatty liver disease (NAFLD) has been increased worldwide

Hepatic fibrosis is an important factor in morbidity and mortality due to liver failure, cardiovascular events, and metabolic disorders

Currently no approved treatment is available

This study aimed to explore the effect of empagliflozin versus pioglitazone and placebo on liver steatosis and fibrosis in patients with T2DM and NAFLD

Compared to placebo, empagliflozine improves the CAP score and liver stiffness measurement (LSM) in patients with nonalcoholic fatty liver disease and type 2 diabetes mellitus

Empagliflozin decreases LSM more effectively than pioglitazone

Body weight and abdominal fat area decrease with empagliflozin

\section{DIGITAL FEATURES}

This article is published with digital features, including a summary slide, to facilitate understanding of the article. To view digital features for this article go to https://doi.org/10.6084/ m9.figshare.13622393.

\section{INTRODUCTION}

The prevalence of non-alcoholic fatty liver disease (NAFLD) is parallel to obesity, which has been increasing worldwide for the past 30 years [1]. According to one meta-analysis, the prevalence of ultrasound-determined fatty liver in patients with type 2 diabetes mellitus (T2DM) has been reported from 29.6 to $87.1 \%$ [2]. In recent years, NAFLD has become doubly important because of the growing incidence of obesity and T2DM. In susceptible individuals, NAFLD can progress to cirrhosis, end-stage liver disease and hepatocellular carcinoma (HCC). It is predicted that NAFLD will become the main cause of mortality due to liver disease in the next 20 years and will be an important cause for liver transplantation in the next few years [3]. Although its potential for progression to cirrhosis and HCC has been recognized for decades, recent findings suggest that NAFLD is a major cause of cryptogenic cirrhosis [4].

NAFLD is a metabolic disorder caused by a complex interaction among genetic, hormonal, and nutrient factors [5]. Obesity and metabolic syndrome are the most important risk factors for NAFLD, with T2DM and hypertension being associated with further disease progression $[6,7]$. An important pathogenic mechanism of both NAFLD and T2DM is insulin resistance. T2DM also worsens liver steatosis leading to $\mathrm{NASH}$, fibrosis, and cirrhosis, and ultimately to increased risk of developing HCC [7-9]. On the other hand, NAFLD patients have an increased risk of diabetes [10]. Moreover, advanced hepatic fibrosis is known as an independent factor in predicting mortality $[11,12]$ and is considered an independent risk factor for cardiovascular events associated with reduced life expectancy [13, 14]. Some data suggested 
NAFLD is associated with cardiac arrhythmia and venous thrombosis [15].

As NAFLD and non-alcoholic stateohepatitis (NASH) are closely related to macro-cardiovascular events and are associated with reduced life expectancy, early and appropriate therapeutic intervention is essential [16]. However, despite the role of incretin hormones in NAFLD pathogenesis [17] and various interventions targeting the gut-pancreas-liver axis, in NASH treatment no approved treatment is currently available $[17,18]$.

Sodium-glucose cotransporter 2 (SGLT2) inhibitors prevent glucose reabsorption in renal proximal tubules, leading to increased urinary glucose excretion and a decrease in the blood glucose and insulin levels $[19,20]$. This class of medications reduces macrovascular events $[19,20]$ and also has beneficial effects on liver function, in both clinical trials and animal models [21-23]. Therefore, SGLT2 inhibitors could prove to be useful in the treatment of patients with T2DM with NAFLD. On the other hand, thiazolidinediones that target and decrease insulin resistance, adipose tissue dysfunction, and inflammation are accepted to be useful in the treatment of these patients [24], and studies using pioglitazone have shown improvements in insulin resistance as well as in laboratory and histology indices of liver pathology in patients with fatty liver [25-28].

This study aimed to explore the effect of empagliflozin versus placebo on liver steatosis and fibrosis in patients with T2DM and NAFLD. The results would be compared to those in a similar group of patients treated with pioglitazone, an agent that has shown efficacy in some patients with NAFLD and T2DM.

\section{METHODS}

\section{Study Design}

This was a 24-week, prospective, randomized, double-blind, placebo-controlled clinical trial, using 1:1:1 allocation to the treatment arms using a computer-generated randomization sequence. It was in accordance with the principles of the Declaration of Helsinki and was approved by the Ethics Committee of Iran University of Medical Sciences (ethics code. R.IUMS.FMD.REC.1398.463). The study was also registered in the Iranian Registry of Clinical Trials (IRCT), registration number: IRCT20190122042450N3). All the participants signed written informed consent before enrolment. Data management was performed by the Institute of Endocrinology and Metabolism monitoring committee, which was blinded to the study arms. Abidi Pharmaceuticals supplied empagliflozin, pioglitazone, and placebo and had no other role in the study.

\section{Patients}

Patients with T2DM, aged 20 and 65 years, with a hemoglobin A1c (HbA1c) of $7-10 \%$ were eligible to enroll. Inclusion criteria were established T2DM and NAFLD with controlled attenuation parameter $(\mathrm{CAP}) \geq 238 \mathrm{~dB} / \mathrm{m}$ in transient hepatic elastography [29]. Exclusion criteria included: type 1 diabetes; active or chronic hepatitis; cirrhosis and biliary disease; heart failure defined as New York Heart Association (NYHA) class III and IV; renal dysfunction estimated glomerular filtration (eGFR) $<45 \mathrm{ml} /$ $\min / 1.73 \mathrm{~m}^{2}$ ); history of alcohol consumption $>20 \mathrm{~g}$ per day in women and $30 \mathrm{~g}$ per day in men; taking medications associated with fatty liver nonsteroidal anti-inflammatory drugs (NSAIDs) (amiodarone, tamoxifen, sodium valproate, corticosteroids, methotrexate); taking other fatty liver-related therapies such as vitamin $\mathrm{E}$ and trial medications (empagliflozin and pioglitazone); using supplements including vitamin $\mathrm{C}$, zinc, selenium, or antioxidant agents over the last months; history of cardiovascular events within the past 3 months; pregnancy and breastfeeding; active cancer or history of cancer treatment over the past 2 years; untreated thyroid disorder; body mass index $(\mathrm{BMI}) \geq 40 \mathrm{~kg} / \mathrm{m}^{2}$.

\section{Randomization and Masking}

Eligible subjects were randomly assigned to the three study arms using a random block method to receive empagliflozin $10 \mathrm{mg}$ once daily, 
pioglitazone $30 \mathrm{mg}$ once daily, or placebo once daily for 24 weeks. Both the investigators and patients were blinded to the study arms, and measurement of end points was performed by clinicians and technicians who were not aware of the randomization groups and treatment arms. Also, all of the pills were concealed and did not have a visible name or information.

\section{Procedures}

All baseline measurements were performed within 1 week of enrollment. Fibroscan, dualenergy $\mathrm{x}$-ray absorptiometry (DEXA) scan, and the biochemical variables were re-measured at week 24 with the same device and method and by the same physician who was blinded to the study arms. Liver fibroscan was performed by FibroScan ${ }^{\circledR} 502$ Touch equipped with both $\mathrm{M}$ and XL probes. Controlled attenuation parameter (CAP) and liver stiffness measurement (LSM) were determined, as described [29]. CAP was deemed valid only in matched LSM values to ensure the accuracy of the measurements. According to the usual definition, all the following criteria had to be met to consider LSM as reliable: ten valid measurements, LSM success rate $60 \%$, and LSM interquartile range/median (IQR/M) 0.30 [30-32]. Participants with CAP score $>238 \mathrm{~dB} / \mathrm{m}$ were enrolled in the study $[29,33,34]$. Fibrosis was also determined using the METAVIR score according to a previous study [35]. In addition, a DEXA scan (Hologic Discovery DXA system) was performed in all participants. Full-body DXA in supine position was performed for analysis of lean and fat masses. We calculated two indices using the appendicular lean mass (ALM) (kg): ALM divided by height squared $\left(\mathrm{kg} / \mathrm{m}^{2}\right)$; ALM divided by weight and multiplied by $100(\mathrm{~kg} / \mathrm{kg} \times 100)$. Skeletal muscle index (SMI) (ALM/height ${ }^{2}$ ) was categorized to low risk (\%): men $<7$ and women $<5.4$; high risk: (\%) men $\geq 7$ and women $\geq 5.4$. SMI (ALM/weight) was categorized as low risk (\%): men $\leq 29$ and women $\leq 25$; high risk (\%): men $>29$ and women $>25$ $[36,37]$.

Lipid profile, fasting blood sugar (FBS), serum aspartate aminotransferase (AST), and alanine aminotransferase (ALT), serum creatinine (Pars biochemical kits using the photometric method), HbA1c (SEBIA using the capillary method), fasting insulin [Monobind kit, code: 5825-300, immunoenzymometric assay ("IEMA" method], and complete blood count (Sysmex cell counter device using the electric resistance-light scattering method) were measured at baseline and the end of the study. We also measured viral hepatitis markers (hepatitis B via SURASE B-96 kit and hepatitis C via NANBASE C 96 Kit), ANA (EUROIMMUN kit using the immunofluorescence method), and thyroid function (ELISA, Pishtaz Medical Co.).

NAFLD fibrosis risk score was calculated by the following formula (38): NAFLD fibrosis score $=-1.675+(0.037 \times$ age $\quad$ [years] $)+$ $\left(0.094 \times\right.$ BMI $\left.\left[\mathrm{kg} / \mathrm{m}^{2}\right]\right)+(1.13 \times$ IFG/diabetes [yes $=1$, no $=0])+(0.99 \times$ AST $/$ ALT ratio $)-$ $\left(0.013 \times\right.$ platelet count $\left.\left[\times 10^{9} / 1\right]\right)-(0.66 \times$ albumin $[\mathrm{g} / \mathrm{dl}])$. NAFLD fibrosis score was categorized as low risk $(\%):<-1.455$, intermediate risk (\%): - 1.455-0.675, and high risk (\%): $>0.675$. Furthermore, the FIB-4 (fibrosis 4) index [39] was calculated using the following formula: FIB- 4 index $=[$ age $\times$ AST $($ units $/ \mathrm{l})] /(-$ platelet count $\left(\times 10^{9} / \mathrm{l}\right) \times[\text { ALT (units/l) }]^{1 / 2}$. The FIB4 index was categorized as low risk $(\%):<1.3$, intermediate risk (\%): $1.3-2.67$, and high risk $(\%):>2.67$. Also, we calculated the APRI (aspartate aminotransferase to platelet ratio index) [40] by the following formula: $\mathrm{APRI}=[(\mathrm{AST} / \mathrm{AST}$ upper limit of nor$\mathrm{mal}) /$ platelet $\left.\left(\times 10^{9} / \mathrm{l}\right)\right] \times 100$ and categorized it as low risk (\%): $<0.5$, intermediate risk (\%): $0.5-1.5$ and high risk (\%): $>1.5$.

Insulin resistance was estimated by calculating HOMA2-IR, using the HOMA Calculator and HOMA-IR by the following formula: FBS $(\mathrm{mg} / \mathrm{dl}) \times$ fasting serum insulin $(\mu \mathrm{IU} / \mathrm{ml}) / 405$. [41].

\section{Follow-Up}

Participants were asked to perform moderateintensity physical activity based on a metabolic equivalent task (METS) at least 3 times a week, and they were encouraged to follow the recommendation at least $45 \mathrm{~min}$ without 
interruption during the study period. Participants were given standard dietary advice as well.

Participants were followed monthly by phone calls to assess their adherence to the treatment protocol and presence of possible adverse events including genital or urinary tract infections, hypoglycemia, lower extremity edema, shortness of breath, nausea, angioedema, or drug intolerance and other adverse events. All patients had an in-clinic visit 3 months after enrollment and at the end of the study.

\section{Outcomes}

The primary end point was the change in CAP score from baseline to 24 weeks of treatment. The key secondary end point was the change in LSM from baseline to 24 weeks of treatment. Other secondary end points were the changes in liver enzymes (AST, ALT), fasting insulin, HOMA2 IR, VAT (visceral adipose tissue), and body composition parameters as well as noninvasive measurement scores for hepatic fibrosis.

\section{Statistical Analysis}

We calculated that a sample of 75 patients (total with 25 per group) would be required to detect a difference of $28.2 \mathrm{~dB} / \mathrm{m}$ ( $9 \%$ from base) in the CAP score, with $80 \%$ power at a significance level of $0.05[42,43]$. Assuming up to a $30 \%$ drop out, the sample size was 105 participants [35].

All analyses for the efficacy parameters were performed in the intention-to-treat population. Baseline characteristics of the participants were summarized as means \pm standard deviation (SD) for continuous variables and percentages for categorical variables. For continuous variables, paired $t$ test was used to compare before/ after measurements, and comparison of differences in each group was performed using analysis variance (ANOVA). Also, for continuous variants, only measured at baseline, ANOVA was used. Comparisons of discrete covariates between the groups and the before/after measurements were done using the chi-squared test. All $p$-values presented are two-tailed, and differences were considered statistically significant at $p<0.05$. Finally, the regression models with repeated measures were fitted to assess the effects of the covariates on the outcomes.

\section{RESULTS}

\section{Study Population}

A total of 186 individuals were screened according to the inclusion/exclusion criteria, and 106 individuals who met the eligibility criteria were randomized to receive empagliflozin $(n=35)$, pioglitazone $(n=35)$, or placebo $(n=36)$. Of all randomized patients, 78 completed the trial (empagliflozin group, $n=25$; pioglitazone group, $n=27$, and placebo group, $n=26$ ). The patient enrollment flow diagram and the reasons for drop-out are shown in Fig. 1.

\section{Patient Characteristics}

At baseline, the three groups were matched regarding to demographic and anthropometric characteristics. The duration of T2DM (about 6.5 years), statin consumption, and biochemical indices were comparable among the three groups (Table 1).

In the empagliflozin group, weight and BMI decreased significantly ( $p<0.001$ for both), while in the pioglitazone group, both body weight and BMI had increased significantly by the end of the trial $(p=0.007$ and $p=0.005$, respectively). In the placebo group, there was no significant change in these parameters.

\section{Liver Enzymes and Insulin Resistance State}

After 24 weeks, AST levels decreased significantly in the empagliflozin group $(p=0.02)$, and both AST and ALT levels decreased in the pioglitazone group $(p=0.03$ and $p=0.01$, respectively). 


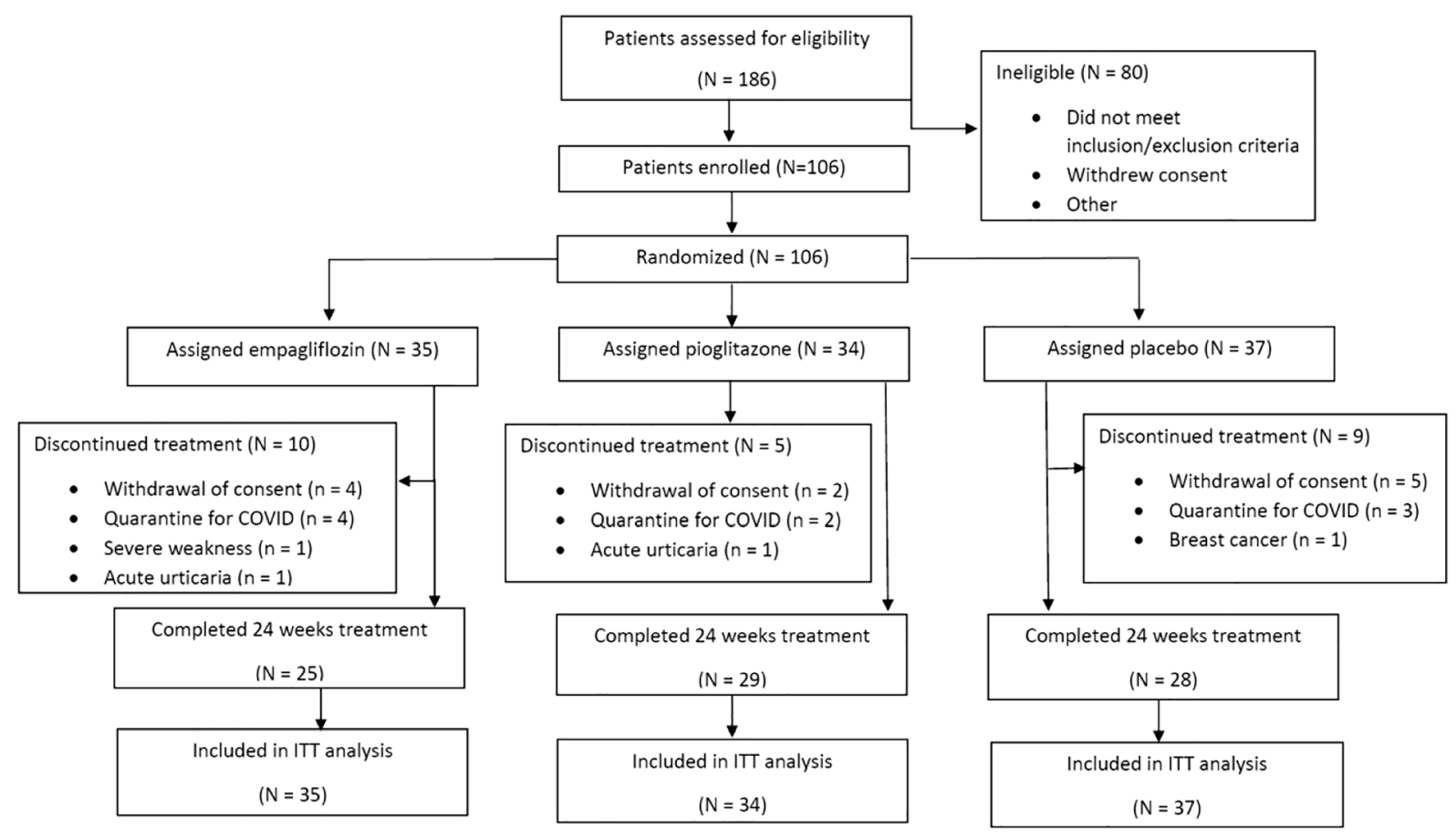

Fig. 1 Patient enrollment flow diagram. ITT intention to treat

In addition, by the end of the trial, there was a significant decrease $(p=0.008)$ in fasting insulin levels in the pioglitazone group $(14.7 \pm 6.2 \mathrm{mIU} / \mathrm{l}$ to $12.2 \pm 3.8 \mathrm{mIU} / \mathrm{l})$ with no significant change in the empagliflozin or placebo groups. HOMA2 IR was significantly decreased $(2.1 \pm 0.9$ to $1.7 \pm 0.5 ; p=0.01)$ in the pioglitazone group, and the small change in the empagliflozin group did not reach statistical significance $(2.4 \pm 1.2$ to $2.2 \pm 1.1 ; p=0.14)$. The same pattern was observed for HOMA-IR, namely that in the pioglitazone group, HOMAIR decreased significantly from $6.0 \pm 2.5$ to $4.3 \pm 1.7(p<0.001)$ and the smaller decrease in the empagliflozin group did not reach significance $(6.3 \pm 4.4$ to $5.7 \pm 3.7 ; p=0.27)$. Changes in AST, ALT, fasting insulin, HOMA-IR, and HOMA2-IR were comparable between the pioglitazone and empagliflozin groups $(p=0.43,0.81,0.36,0.10$, and 0.48 , respectively, for between groups).

\section{Metabolic Profile}

After 24 weeks, the HbA1C level decreased significantly in both the empagliflozin and pioglitazone groups $(p=0.001$ and $<0.001$, respectively); however, the reduction was greater in the pioglitazone group $(p=0.01)$. Also, there was a significant decrease in FBS levels in the pioglitazone group $(p<0.001)$. At the end of the trial, there was no significant change in low-density lipoprotein (LDL) and triglyceride (TG) levels in any of the groups, but there was a significant increase in the highdensity lipoprotein (HDL) level in the pioglitazone group $(p=0.002)$.

\section{Liver Steatosis (CAP) and Fibrosis (LSM)}

The CAP score was not significantly different between the three groups at baseline $(p=0.11)$. It decreased from $317.37 \pm 28.46 \mathrm{~dB} / \mathrm{m}$ to $287.80 \pm 31.14 \mathrm{~dB} / \mathrm{m}(p<0.001)$ in the empagliflozin group, from $308.76 \pm 30.59 \mathrm{~dB} / \mathrm{m}$ to $280.91 \pm 34.52(p<0.001)$ in the pioglitazone group, and from $313.14 \pm 30.40 \mathrm{~dB} / \mathrm{m}$ to 


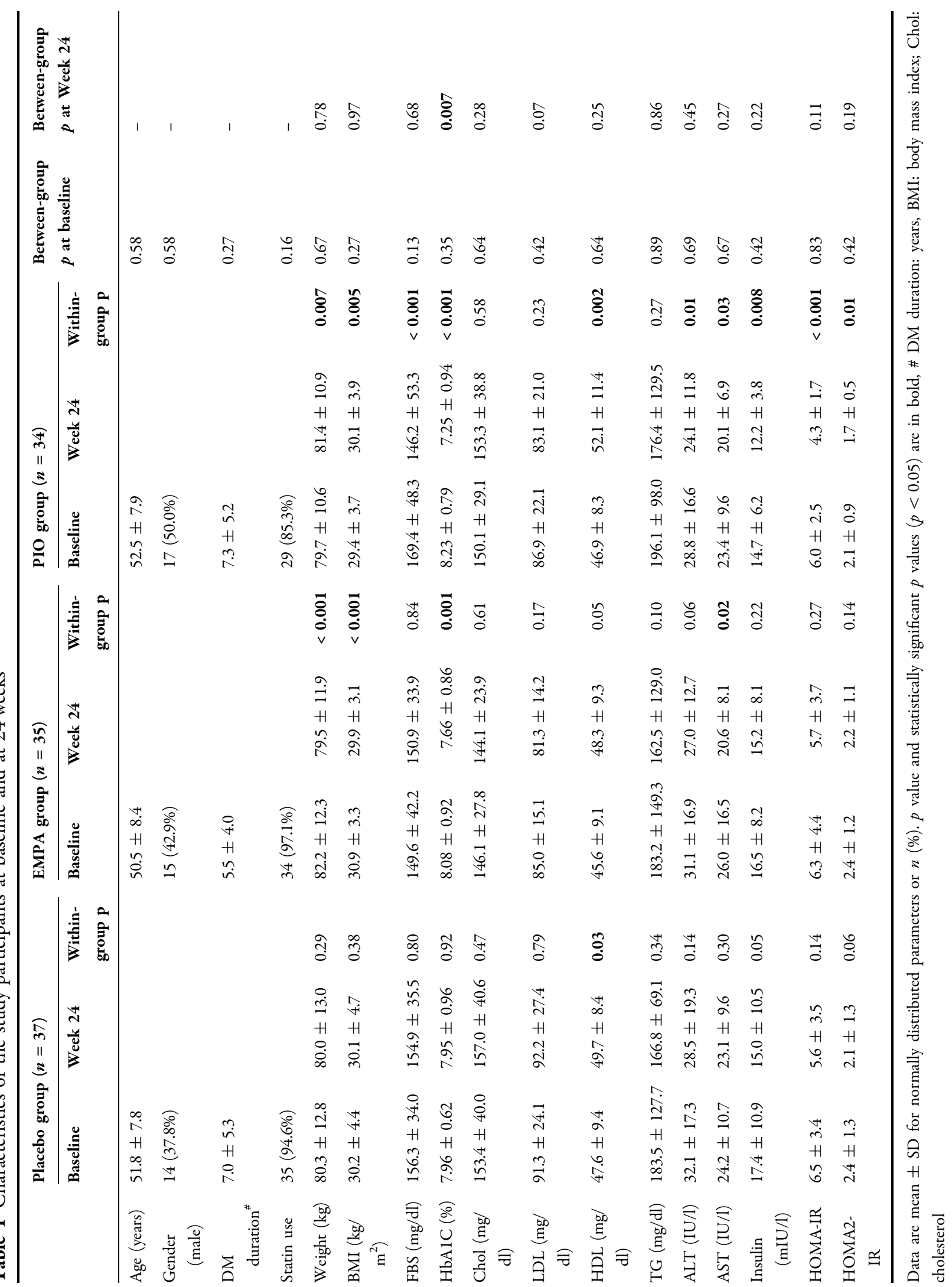


$296.73 \pm 40.13$ in the placebo group $(p<0.001)$ (Table 2).

Compared to the placebo group as the reference, there was a borderline significant decrease in the CAP score in the empagliflozin group ( $p=0.05$ ), while no significant change was observed in the pioglitazone group $(p=0.08)$. The distribution of CAP scores at baseline and at the end of the study among the participants is shown in Fig. $2 \mathrm{a}$.

Liver fibrosis, was significantly decreased after 24 weeks in the empagliflozin group (LSM: $6.83 \pm 2.44$ to $6.01 \pm 1.65 \mathrm{kPa} ; p=0.005$ ), while the change in fibrosis score in the pioglitazone group and placebo groups was not significant: $\quad(6.48 \pm 1.67$ to $6.42 \pm 2.14 \mathrm{kPa}$; $p=0.80)$ and $(7.49 \pm 2.65$ to $7.17 \pm 2.67 \mathrm{kPa}$; $p=0.27$ ), respectively (Table 2 ).

In univariate regression analysis, changes from baseline in HOMA2-IR $(p=0.06)$, BMI $(p=0.21)$, and HbA1c $(p=0.33)$ were not associated with the degree of liver fibrosis at the end of the study. In multivariate analysis, after adjusting for baseline covariates, we found a significant difference between the empagliflozin and placebo groups in relation to liver fibrosis at the end of the study: $-0.77(p=0.02)$; however, there was no significant difference between the pioglitazone and placebo groups: $0.01(p=0.98)$.

Additionally we found that a lower HOMA2IR at baseline was associated with a lower fibrosis score, while BMI, age, gender, and HbA1c did not have any association with liver fibrosis. In this model, one unit lower HOMA2IR at baseline was associated with a 0.34 lower fibrosis score $(p=0.02)$ (Table 3$)$. The distribution of fibrosis scores at baseline and at the end of the study is shown in Fig. 2b.

\section{Non-Invasive Scoring Systems for Assessment of NAFLD}

There were no significant changes in the noninvasive scoring for liver fibrosis, including the NAFLD fibrosis score and FIB-4 index. However, there was a numerical decrease in the number of individuals in the empagliflozin group who 

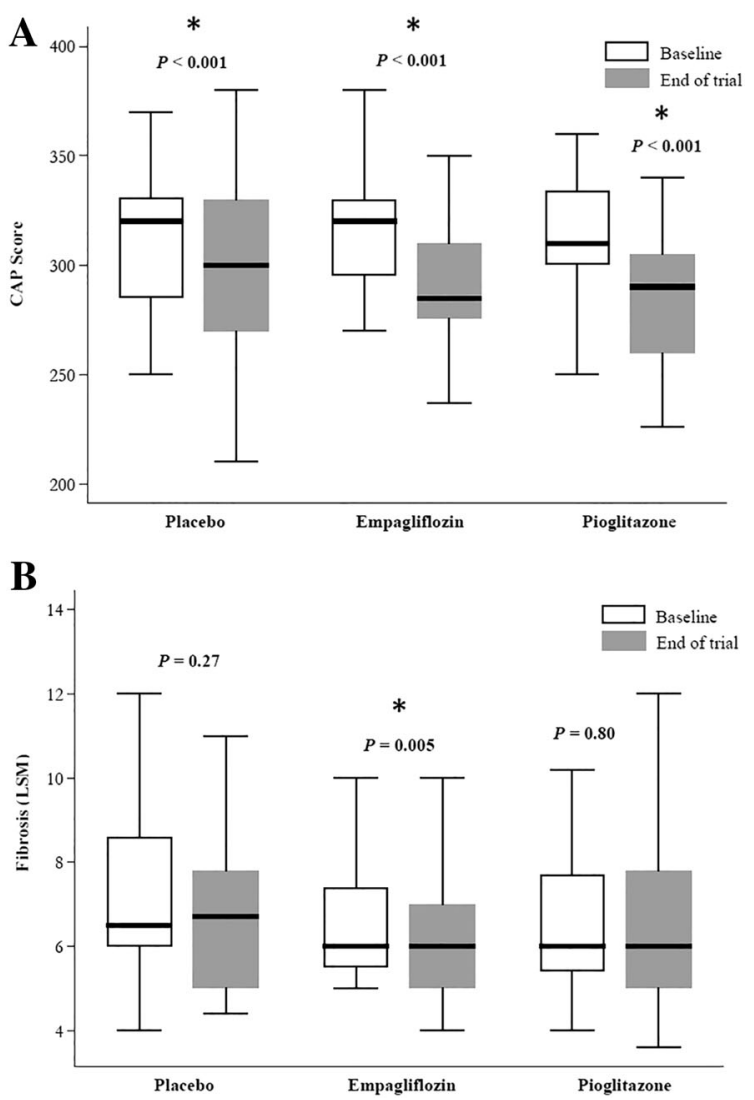

Fig. 2 a Distribution of CAP score stratified by the study groups. White boxes show the CAP score at baseline, and black ones indicate the final results after the intervention. ${ }^{*} p<0.05$ compared with baseline and significant results. b Distribution of liver stiffness measurement stratified by the study groups. White boxes show liver stiffness measurement at baseline, and black ones indicate final results after the intervention. ${ }^{*} p<0.05$ compared with baseline and significant results

were classified in the intermediate risk category of the FIB-4 index (25.7-20\%) (see Appendix).

In evaluating the APRI parameter, there was a numerical decrease in the number of individuals at the intermediate risk (11.8-5.9\%) in the pioglitazone group, but this change was not statistically significant $(p=0.31)$. In the empagliflozin group, a decrease in the number of intermediate risk individuals and their conversion to low risk individuals (20-5.7\%) resulted in a statistically significant difference $(p=0.02)$ (see Appendix).

\section{Changes in Body Composition}

After 24 weeks, there was a significant increase in truncal fat mass area in the pioglitazone and placebo groups ( $p<0.001$ in both), while in the empagliflozin group the modest increase was not statistically significant $(p=0.12)$ (Table 4$)$. Although, there was no significant difference among the three groups regarding changes in the $\operatorname{VAT}(p=0.57)$, the VAT area increased significantly in the pioglitazone and placebo groups ( $p=0.006$ and 0.005 , respectively). The VAT area did not change in the empagliflozin group from the baseline $(p=0.85)$. There was a significant difference in the change in VAT area and truncal fat mass in the empagliflozin group compared to the pioglitazone group $(p=0.01$ and $<0.001$, respectively).

There was a significant decrease in the skeletal muscle index (SMI) when ALM was adjusted for height ${ }^{2}$ in all groups. Given that the height was constant throughout the study, this finding suggests that ALM significantly decreased in all groups; however, changes were not significant among the the groups $(p=0.82)$. Furthermore, we found a significant decrease in SMI per weight (ALM/weight) in all groups with no significant difference among groups $(p=0.80)$ (Table 4$)$.

A statistically significant decrease was observed in the pioglitazone and empagliflozin groups in their android/gynoid (A/G) ratio and AFR (android fat ratio), while no significant change was observed in the placebo group and when compared among the three groups (Table 4).

\section{Adverse Events}

One patient in each of the groups had an episode of mild hypoglycemia. Other adverse events included two cases of urticaria (one each in the empagliflozin and pioglitazone groups), a case of nocturia and polyuria in the empagliflozin group, and one case of severe weakness and fatigue leading to discontinuation of the medication in the empagliflozin group. Also, one case of diabetic foot ulcer was seen in the placebo and in the pioglitazone groups. There 
Table 3 Multivariate analysis of fibrosis (LSM)

\begin{tabular}{|c|c|c|c|c|c|c|}
\hline & & \multirow[t]{2}{*}{ Coefficient } & \multirow[t]{2}{*}{ Multivariate $p$ value } & \multicolumn{2}{|c|}{ 95\% Confidence interval } & \multirow{2}{*}{$\begin{array}{l}\text { Comparing empagliflozin } \\
\text { with pioglitazone } p \text { value }\end{array}$} \\
\hline & & & & Lower & Upper & \\
\hline \multirow[t]{2}{*}{ Groups } & Empagliflozin & -0.77 & 0.02 & -1.45 & -0.09 & 0.03 \\
\hline & Pioglitazone & 0.01 & 0.98 & -0.70 & 0.71 & \\
\hline \multirow[t]{5}{*}{ Variates } & HOMA2-IR & 0.34 & 0.02 & 0.04 & 0.64 & \\
\hline & BMI & 0.07 & 0.07 & -0.01 & 0.15 & \\
\hline & Age & 0.10 & 0.61 & -0.03 & 0.05 & \\
\hline & Gender & 0.32 & 0.28 & -0.27 & 0.91 & \\
\hline & HbA1C & 0.04 & 0.82 & -0.32 & 0.40 & \\
\hline
\end{tabular}

Statistically significant $p$ values $(p<0.05)$ are in bold

was one case of breast cancer in the placebo group; this was discovered during an annual screening program, and the participant was excluded from continuing in the study.

\section{DISCUSSION}

In this randomized, double-blind, placebo-controlled trial, we found that treatment with $10 \mathrm{mg} /$ day of empagliflozin for 24 weeks improved hepatic steatosis and fibrosis in patients with T2DM and NAFLD.

\section{CAP Score and Liver Function}

Visceral adiposity and liver fat accumulation predispose individuals with NAFLD to extrahepatic disorders including cardiovascular diseases, chronic kidney disease, T2DM, and colorectal cancer [44-46]. Liver biopsy remains the gold standard in assessment of NAFLD. However, limited studies have used this method to evaluate the efficacy of SGLT2 inhibitors on NAFLD progression [47]. Biopsy-proven improvement of liver histology has been reported in patients treated with empagliflozin [48]. A limitation of this study was the lack of a true placebo arm along with its open-label design. Recent studies have shown that fibroscans can effectively evaluate the liver steatosis percentage and its grade compared to liver histology as the gold standard. [33, 35]. In addition, a large-scale prospective study demonstrated the accuracy of CAP for the diagnosis of NAFLD [35].

Here, we assessed the effect of empagliflozin and pioglitazone by measuring CAP as an index of hepatic steatosis [35]. Compared to placebo, empagliflozin patients had a marginally significant improvement in hepatic steatosis, while no significant change was observed with pioglitazone.

Previous studies have examined the effects of various SGLT2 inhibitors on patients with T2DM and NAFLD [18, 43, 49-52]. They showed improvement in at least one liver enzyme level $[31,43,49,50,52]$ and in hepatic fat content $[43,49,52]$. An absolute reduction in liver fat content has been reported in patients with NAFLD treated with empagliflozin in the E-LIFT Trial. In this study, 4\% reduction in absolute liver fat was associated with improvement of steatosis [49]. However, they used MRI-PDFF, which is expensive and time-consuming [53]. A study from Japan reported that ipragliflozin (a SGLT-2 inhibitor) reduced liver fat in patients with T2DM and NAFLD. However, the authors used the fatty liver index for the assessment of liver fat [54]. Moreover, similar results have been described in patients treated with luseogliflozin using the liver-to-spleen (L/S) 


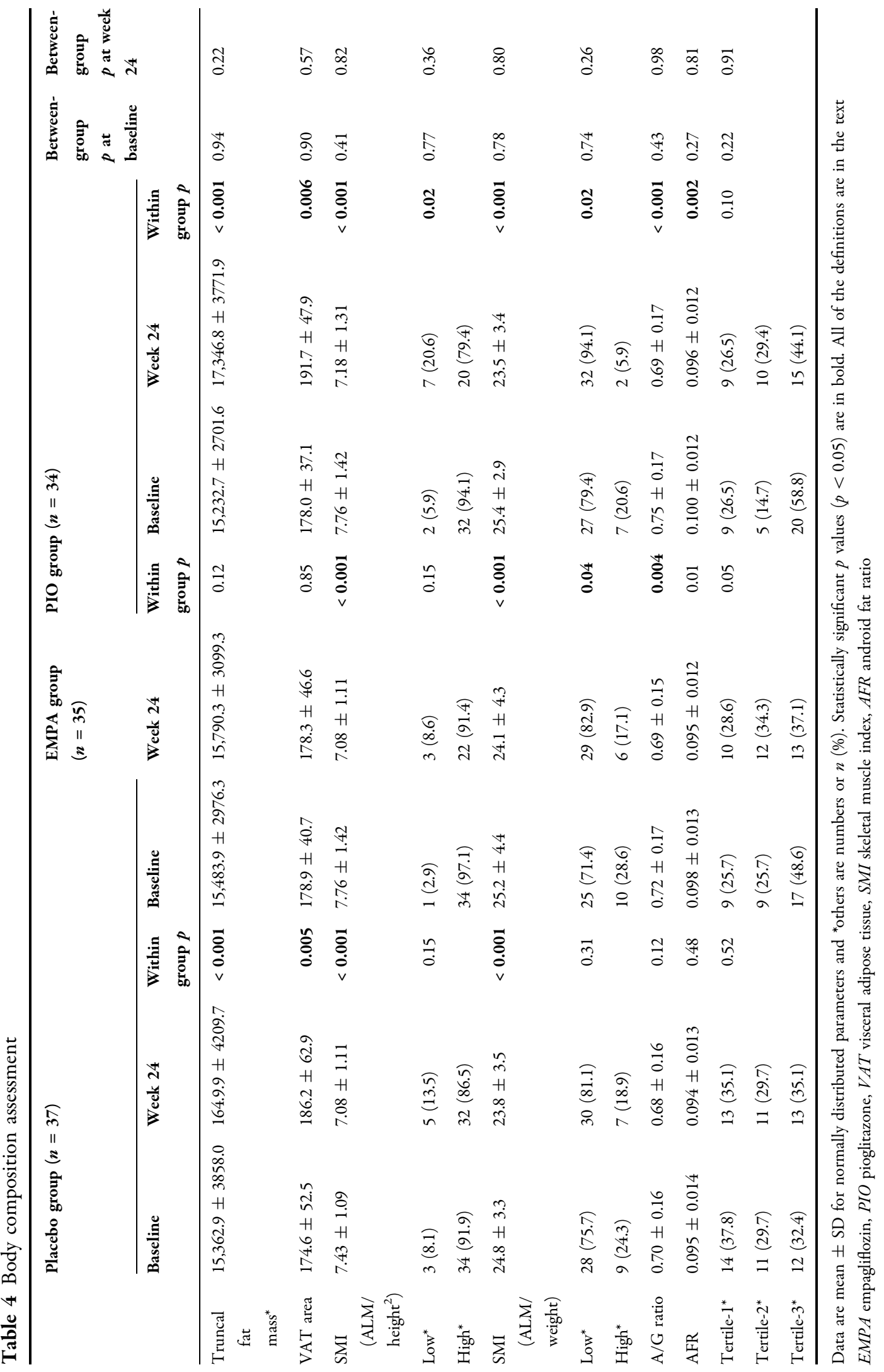


attenuation ratio to estimate liver fat. However, this method is not accurate for quantifying liver fat content [52]. Similar to our study, Shimizu et al. reported improvement of the CAP score with dapagliflozin vs. placebo [43]. Moreover, ipragliflozin was compared with pioglitazone, and the results showed a reduction of $\mathrm{L} / \mathrm{S}$ on computed tomography (CT) scan but no significant difference was observed between ipragliflozin and pioglitazone [18].

We also demonstrated improvement in liver enzymes with pioglitazone and reduction of AST in patients treated with empagliflozin. This finding has been demonstrated by others who found a significant decrease in serum ALT levels $(p=0.006)$ after ipragliflozin treatment [54]. Another study showed that the use of ipragliflozin in patients with T2DM and NAFLD improved serum AST and gamma-glutamyl transferase (GGT) levels [44]. Furthermore, canagliflozin improved the serum ALT level in patients with T2DM [55], and improvement in liver enzymes was reported in the E-LIFT [49] and PIVENS studies [56]. However, similar to our results, a study comparing ipragliflozin with pioglitazone reported no significant difference in the reduction of AST and ALT levels [18].

\section{Liver Stiffness Measurement}

In this study, a liver fibroscan was used to evaluate fibrosis. It has been shown that LSM reliably estimates liver fibrosis [57]. We detected a significant decrease in liver fibrosis after 24 weeks of treatment with empagliflozin $(p=0.005)$, while no change was observed with use of pioglitazone. Another study showed improvement of LSM in patients with T2DM who were treated with dapagliflozin, although the improvement was significant in the subgroup with significant liver fibrosis at baseline [43]. Also, an umbrella review indicated SGLT2 inhibitors effectively decrease liver steatosis, but not liver fibrosis, in diabetic patients with NAFLD [58]. However, one recent trial in nondiabetic patients with NAFLD showed improvement of the CAP score and LSM with empagliflozin vs. placebo [59].
The PIVENS trial compared the effects of a 2-year treatment with low-dose pioglitazone and vitamin $\mathrm{E}$ versus placebo in patients with T2DM [56]. The results showed that pioglitazone improved all histological features except for fibrosis and reduced the stage of NASH more than the placebo group [56]. By activating PPAR $r$, glitazones sensitize adipose tissue to insulin, thereby stimulating uptake and storage of fatty acids [60]. Also, by increasing adiponectin and reducing pre-inflammatory adipokines, they lead to decreased gluconeogenesis and the influx of fatty acids and improve insulin sensitivity [61]. Use of this class of medications improves adipose tissue function and leads to improvement in hepatic steatosis [25].

In a placebo-controlled study, Cusi et al. reported that patients with T2DM and NASH who were treated with pioglitazone showed improvement in their hepatic steatosis as well as in inflammation and ballooning [25]. There was also improvement in fibrosis and insulin sensitivity in the liver, skeletal muscle, and adipose tissue; these changes were maintained for 36 months after treatment [25]. Belfort et al. in a 6-month clinical trial in patients with pre-diabetes or T2DM with proven NASH by liver histology reported that pioglitazone caused a significant improvement in liver steatosis and inflammation; furthermore, the NAFLD activity score (NAS) improved in $73 \%$ of patients who were treated with pioglitazone compared with $24 \%$ in the placebo group $(p<0.001)$ [28].

The mechanisms leading to a beneficial effect of empagliflozin on liver fibrosis are not well understood. Inhibition of proinflammatory cytokines such as IL- 6 , TNF- $\alpha$, and MCP- 1 might be one possible explanation. [62]. Thus, inhibition of inflammation in the liver may contribute to inhibition of hepatic fibrosis in patients with NAFLD who are treated with empagliflozin.

We found that empagliflozin improved liver fibrosis compared with pioglitazone or placebo $(p=0.03)$. In addition, our study provides evidence on relationship between HOMA2-IR, an index of insulin resistance, and liver stiffness, while HbA1c, BMI, age, and gender were not associated with liver fibrosis. Fujii et al. showed that HOMA-IR and age are independent 
predictors of advanced fibrosis in patients with NAFLD but without T2DM [63]. In contrast, a cross-sectional study in children with obesity and diabetes mellitus showed that HOMA-IR is not an independent predictor of liver fibrosis assessed by LSM [64].

On the other hand, Watt et al. presented evidence of a relationship between glycemic control and liver stiffness [65]. Also, in a cohort study Tanaka et al. reported that HbA1c is significantly associated with liver fibrosis as assessed by the FIB4 index [66]. Furthermore, a prospective study found that although HOMA IR and BMI were independent factors associated with significant liver fibrosis, the HbA1c level was not a significant factor when compared between subjects with and without significant liver fibrosis (liver stiffness $>7.0 \mathrm{kPa}$ ) [67].

\section{Insulin Resistance}

We also found a significant decrease in the fasting insulin level in the pioglitazone group, while no change was observed in the empagliflozin or placebo groups. Suppression of insulin resistance and hepatic steatosis are reported with empagliflozin in mice. This might be due to the anti-inflammatory effect of empagliflozin on fat tissue and liver [68]. However, in our study, a significant decrease in insulin resistance as estimated by the HOMA-IR and HOMA2-IR was seen only in the pioglitazone group ( $p<0.001$ and $p=0.01$, respectively); the modest decreases in the empagliflozin and placebo groups were not statistically significant. In this regard, Shimizu et al. found a significant decrease in insulin resistance measured as HOMA-IR in the dapagliflozin-treated group in a randomized, active controlled, placebo-based open-label trial in patients with T2DM and NAFLD at 24 weeks [43]. However, while the effect of pioglitazone on insulin sensitivity is widely accepted, Ito et al. did not detect any significant difference between the effect of pioglitazone and ipragliflozin on insulin sensitivity [18].

\section{Non-Invasive Scoring Systems}

In our study there were no significant changes in non-invasive scores for measurement of liver fibrosis, namely, the FIB4 index and APRI. The FIB-4 index is a simple and valuable marker of liver fibrosis. While some studies did not find a significant change from baseline in liver fibrosis $[43,69,70]$, others reported SGLT2 inhibitors effectively decrease the FIB-4 index. [18, 71]. In another study, the APRI index decreased significantly with pioglitazone [72]. Moreover, empagliflozin has been reported to lower the APRI index [73]. However, the FIB-4 index did not decrease significantly in the last two studies $[72,73]$. On the other hand, Ito et al. reported a reduction of the FIB4 index with either ipragliflozin or pioglitazone [18]. The reasons for these discrepancies are uncertain. Patients' clinical characteristics and different durations of followup could partly explain different outcomes. Moreover, in our study, a higher percentage of the subjects was in the low-risk group. Hence, it might be difficult to show an improvement in this group of patients after 24 weeks.

\section{Body Composition}

Considering the importance of fat distribution, we also determined the body composition using DXA. This method involves less interference from body fluids than the bioimpedance method. In addition, DXA is a suitable method for measuring the lean mass. Therefore, the SMI, which is based on the lean mass of the extremities, could be a good indicator for the estimation of true skeletal muscle mass [36, 37].

Similar to previous studies [74-77], we found a significant increase in the truncal fat and VAT area with pioglitazone; however, the changes in the empagliflozin group were not significant (see Appendix). In addition, we found a significant decrease in SMI at 24 weeks in all three groups with no difference among the groups. The same reduction for total lean mass was reported in other studies using SGLT2 inhibitors $[73,78,79]$. On the other hand, we found that BMI and weight decreased significantly in the empagliflozin group $(p<0.001)$ while it 
increased significantly in the pioglitazone group ( $p=0.005$ and 0.007 , respectively). It can be hypothesized that decrements in SMI and the loss of skeletal muscle may be caused by increased protein catabolism secondary to calorie loss through glycosuria, and this may lead to sarcopenia, especially in elderly patients [78]. The reduction in muscle mass could itself be part of fatty liver disease [77]. Sasaki, et al. reported that treatment with luseogliflozin induced favorable changes in body composition and metabolism of moderately obese Japanese patients with T2DM accompanied by body fat reduction [80]. Previous studies showed that SGLT2 inhibitor-associated weight loss is mainly attributed to the reduction of fat mass rather than the lean body mass [81, 82].

Although this was the first study comparing the effect of empagliflozin with pioglitazone in patients with T2DM and NAFLD, our study has some limitations. We did not perform liver biopsy as the gold standard to evaluate the status of NAFLD. There was also a relatively large number of drop-outs for various reasons (including COVID-19) in all three groups during the study, which may have decreased the statistical power. However, to address this problem, we repeated the analysis after inclusion of the existing drop-outs and missing data, which showed similar results. Moreover, a longer duration of treatment might be necessary to ascertain effects. The strength of the study includes a reasonable male-to-female ratio of those completing the study (39-52\% males) and the fact that the trial was a double-blind, placebo-controlled study. Finally, all the non-invasive measurements were carried out by the same individual blinded to the study arm of the participants.

\section{CONCLUSION}

In conclusion, this is the first study to investigate the effects of empagliflozin versus pioglitazone on hepatic steatosis and fibrosis in patients with NAFLD and T2DM. We demonstrated that empagliflozin improves steatosis and fibrosis. Further studies are needed to explore the mechanism of action of SGLT2i(s) on NAFLD.

\section{ACKNOWLEDGEMENTS}

We thank the staff of the Endocrine Research Center at Iran University of Medical Sciences (IUMS) for their contribution to this project. Also, we thank the participants of the study.

Funding. No funding or sponsorship was received for this study or publication of this article.

Authorship. All named authors meet the International Committee of Medical Journal Editors (ICMJE) criteria for authorship for this article, take responsibility for the integrity of the work as a whole, and have given their approval for this version to be published.

Authorship Contributions. MEK, HC, and MM made substantial contributions to the conception and design of the study, participated in drafting the article, and revised the article critically for important intellectual content. FI participated in drafting the article and revised it critically for important intellectual content. MRB, FZ, HA, MK, and AEF made substantial contributions to the conception and design of the study and revised it critically for important intellectual content. All authors gave final approval to the version to be submitted and any revised version.

Disclosures. Haleh Chehrehgosha, Masoud Reza Sohrabi, Faramarz Ismail-Beigi, Mojtaba Malek, Mohammad Reza babaei, Farhad Zamani, Hossein Ajdarkosh, Mahmood Khoonsari, Afshin Eshghi Fallah, and Mohammad E. Khamseh have nothing to disclose.

Compliance with Ethics Guidelines. This trial was approved by the Medical Ethics Committee of Iran University of Medical Sciences (ethics code. IR.IUMS.FMD.REC.1398.463), and written informed consent was obtained from all participants. This trial was performed as per the ethics delineated in the Helsinki Declaration. 
This study was registered with the Iranian Registry of Clinical Trials (IRCT), registration number: IRCT20190122042450N3.

Data Availability. The datasets generated during and/or analyzed during the current study are available from the corresponding author on reasonable request.

Open Access. This article is licensed under a Creative Commons Attribution-NonCommercial 4.0 International License, which permits any non-commercial use, sharing, adaptation, distribution and reproduction in any medium or format, as long as you give appropriate credit to the original author(s) and the source, provide a link to the Creative Commons licence, and indicate if changes were made. The images or other third party material in this article are included in the article's Creative Commons licence, unless indicated otherwise in a credit line to the material. If material is not included in the article's Creative Commons licence and your intended use is not permitted by statutory regulation or exceeds the permitted use, you will need to obtain permission directly from the copyright holder. To view a copy of this licence, visit http://creativecommons.org/licenses/by$\mathrm{nc} / 4.0 /$.

\section{REFERENCES}

1. NCD Risk Factor Collaboration. Trends in adult body-mass index in 200 countries from 1975 to 2014: a pooled analysis of 1698 population-based measurement studies with 19. 2 million participants. Lancet. 2016;387(10026):1377-96.

2. Dai W, Ye L, Liu A, Wen SW, Deng J, Wu X, Lai Z. Prevalence of nonalcoholic fatty liver disease in patients with type 2 diabetes mellitus: a metaanalysis. Medicine. 2017;96(39):e8179.

3. Ray K. NAFLD—the next global epidemic. Nat Rev Gastroenterol Hepatol. 2013;10(11):621.

4. Poonawala A, Nair SP, Thuluvath PJ. Prevalence of obesity and diabetes in patients with cryptogenic cirrhosis: a case-control study. Hepatology. 2000;32(4):689-92.
5. Severson TJ, Besur S, Bonkovsky HL. Genetic factors that affect nonalcoholic fatty liver disease: a systematic clinical review. World J Gastroenterol. 2016;22(29):6742-56.

6. Adams LA, Sanderson S, Lindor KD, Angulo P. The histological course of nonalcoholic fatty liver disease: a longitudinal study of 103 patients with sequential liver biopsies. J Hepatol. 2005;42(1): 132-8.

7. Pappachan JM, Antonio FA, Edavalath M, Mukherjee A. Non-alcoholic fatty liver disease: a diabetologist's perspective. Endocrine. 2014;45(3):344-53.

8. Loria P, Lonardo A, Anania F. Liver and diabetes. A vicious circle. Hepatol Res. 2013;43(1):51-64.

9. Petta S, Gastaldelli A, Rebelos E, Bugianesi E, Messa P, Miele L, Svegliati-Baroni G, Valenti L, Bonino F. Pathophysiology of nonalcoholic fatty liver disease. Int J Mol Sci. 2016;17(12):2082.

10. Mantovani A, Petracca G, Beatrice G, Tilg H, Byrne CD, Targher G. Non-alcoholic fatty liver disease and risk of incident diabetes mellitus: an updated metaanalysis of 501022 adult individuals. Gut. 2020. https://doi.org/10.1136/gutjnl-2020-322572.

11. Le MH, Devaki P, Ha NB, Jun DW, Te HS, Cheung RC, Nguyen MH. Prevalence of non-alcoholic fatty liver disease and risk factors for advanced fibrosis and mortality in the United States. PLoS ONE. 2017;12(3):e0173499.

12. Taylor RS, Taylor RJ, Bayliss S, Hagstrom H, Nasr P, Schattenberg JM, Ishigami $\mathrm{M}$, Toyoda $\mathrm{H}$, Wong VW, Peleg N, Shlomai A. Association between fibrosis stage and outcomes of patients with nonalcoholic fatty liver disease: a systematic review and meta-analysis. Gastroenterology. 2020;158(6): 1611-25.

13. Targher G, Day CP, Bonora E. Risk of cardiovascular disease in patients with nonalcoholic fatty liver disease. N Engl J Med. 2010;363(14):1341-50.

14. Doycheva I, Patel N, Peterson M, Loomba R. Prognostic implication of liver histology in patients with nonalcoholic fatty liver disease in diabetes. J Diabetes Complications. 2013;27(3):293-300.

15. Ballestri S, Capitelli M, Fontana MC, Arioli D, Romagnoli E, Graziosi C, Lonardo A, Marietta M, Dentali F, Cioni G. Direct oral anticoagulants in patients with liver disease in the era of non-alcoholic fatty liver disease global epidemic: a narrative review. Adv Ther. 2020;13:1-23.

16. Targher G, Byrne CD, Lonardo A, Zoppini G, Barbui C. Non-alcoholic fatty liver disease and risk of 
incident cardiovascular disease: a meta-analysis. J Hepatol. 2016;65(3):589-600.

17. Svegliati-Baroni G, Patrício B, Lioci G, Macedo MP, Gastaldelli A. Gut-pancreas-liver axis as a target for treatment of NAFLD/NASH. Int J Mol Sci. 2020;16: 5820 .

18. Ito D, Shimizu S, Inoue $\mathrm{K}$, Saito D, Yanagisawa $\mathrm{M}$, Inukai K, Akiyama Y, Morimoto Y, Noda M, Shimada A. Comparison of ipragliflozin and pioglitazone effects on nonalcoholic fatty liver disease in patients with type 2 diabetes: a randomized, 24-week, open-label, active-controlled trial. Diabetes Care. 2017;40(10):1364-72.

19. Zinman B, Wanner C, Lachin JM, Fitchett D, Bluhmki E, Hantel S, Mattheus M, Devins T, Johansen OE, Woerle HJ, Broedl UC. Empagliflozin, cardiovascular outcomes, and mortality in type 2 diabetes. N Engl J Med. 2015;373(22):2117-28.

20. Wu JH, Foote C, Blomster J, Toyama T, Perkovic V, Sundström J, Neal B. Effects of sodium-glucose cotransporter-2 inhibitors on cardiovascular events, death, and major safety outcomes in adults with type 2 diabetes: a systematic review and metaanalysis. Lancet Diabetes Endocrinol. 2016;4(5): 411-9.

21. Bailey CJ, Gross JL, Pieters A, Bastien A, List JF. Effect of dapagliflozin in patients with type 2 diabetes who have inadequate glycaemic control with metformin: a randomised, double-blind, placebocontrolled trial. Lancet. 2010;375(9733):2223-33.

22. Ohki T, Isogawa A, Toda N, Tagawa K. Effectiveness of ipragliflozin, a sodium-glucose co-transporter 2 inhibitor, as a second-line treatment for non-alcoholic fatty liver disease patients with type 2 diabetes mellitus who do not respond to incretin-based therapies including glucagon-like peptide-1 analogs and dipeptidyl peptidase-4 inhibitors. Clin Drug Investig. 2016;36(4):313-9.

23. Tahara A, Kurosaki E, Yokono M, Yamajuku D, Kihara R, Hayashizaki Y, Takasu T, Imamura M, Li Q, Tomiyama H, Kobayashi Y. Effects of SGLT2 selective inhibitor ipragliflozin on hyperglycemia, hyperlipidemia, hepatic steatosis, oxidative stress, inflammation, and obesity in type 2 diabetic mice. Eur J Pharmacol. 2013;715(1-3):246-55.

24. Duvnjak M, Gomerčić M, Tomašić V, Duvnjak LS, Baršić N, Lerotić I. Therapy of nonalcoholic fatty liver disease: current status. J Physiol Pharmacol. 2009;60(S7):57.

25. Cusi K, Orsak B, Bril F, Lomonaco R, Hecht J, OrtizLopez C, Tio F, Hardies J, Darland C, Musi N, Webb A. Long-term pioglitazone treatment for patients with nonalcoholic steatohepatitis and prediabetes or type 2 diabetes mellitus: a randomized trial. Ann Intern Med. 2016;165(5):305-15.

26. Phielix E, Szendroedi J, Roden M. The role of metformin and thiazolidinediones in the regulation of hepatic glucose metabolism and its clinical impact. Trends Pharmacol Sci. 2011;32(10):607-16.

27. Promrat K, Lutchman G, Uwaifo GI, Freedman RJ, Soza A, Heller T, Doo E, Ghany M, Premkumar A, Park Y, Liang TJ. A pilot study of pioglitazone treatment for nonalcoholic steatohepatitis. Hepatology. 2004;39(1):188-96.

28. Belfort R, Harrison SA, Brown K, Darland C, Finch J, Hardies J, Balas B, Gastaldelli A, Tio F, Pulcini J, Berria R. A placebo-controlled trial of pioglitazone in subjects with nonalcoholic steatohepatitis. N Engl J Med. 2006;355(22):2297-307.

29. Eddowes PJ, Sasso M, Allison M, Tsochatzis E, Anstee QM, Sheridan D, Guha IN, Cobbold JF, Deeks JJ, Paradis V, Bedossa P. Accuracy of FibroScan controlled attenuation parameter and liver stiffness measurement in assessing steatosis and fibrosis in patients with nonalcoholic fatty liver disease. Gastroenterology. 2019;156(6):1717-30.

30. Degos F, Perez P, Asselineau J, Bedossa P. Diagnostic accuracy of FibroScan and comparison to liver fibrosis biomarkers in chronic viral hepatitis: a multicenter prospective study (the FIBROSTIC study). J Hepatol. 2011;55(1):234-5.

31. Nobili V, Vizzutti F, Arena U, Abraldes JG, Marra F, Pietrobattista A, Fruhwirth R, Marcellini M, Pinzani M. Accuracy and reproducibility of transient elastography for the diagnosis of fibrosis in pediatric nonalcoholic steatohepatitis. Hepatology. 2008;48(2):442-8.

32. Zarski JP, Sturm N, Guechot J, Paris A, Zafrani ES, Asselah T, Boisson RC, Bosson JL, Guyader D, Renversez JC, Bronowicki JP. Comparison of nine blood tests and transient elastography for liver fibrosis in chronic hepatitis C: the ANRS HCEP-23 study. J Hepatol. 2012;56(1):55-62.

33. Sasso M, Beaugrand M, De Ledinghen V, Douvin C, Marcellin P, Poupon R, Sandrin L, Miette V. Controlled attenuation parameter (CAP): a novel VCTE $^{\mathrm{TM}}$ guided ultrasonic attenuation measurement for the evaluation of hepatic steatosis: preliminary study and validation in a cohort of patients with chronic liver disease from various causes. Ultrasound Med Biol. 2010;36(11):1825-35.

34. Yen YH, Chen JB, Cheng BC, Chen JF, Chang KC, Tseng PL, Wu CK, Tsai MC, Lin MT, Hu TH. Using controlled attenuation parameter combined with ultrasound to survey non-alcoholic fatty liver 
disease in hemodialysis patients: a prospective cohort study. PLoS ONE. 2017;12(4):e0176027.

35. Foucher J, Chanteloup E, Vergniol J, Castera L, Le Bail B, Adhoute X, Bertet J, Couzigou P, de Ledinghen V. Diagnosis of cirrhosis by transient elastography (FibroScan): a prospective study. Gut. 2006;55(3):403-8.

36. Bouchi R, Nakano Y, Ohara N, Takeuchi T, Murakami M, Asakawa M, Sasahara Y, Numasawa M, Minami I, Izumiyama H, Hashimoto K. Clinical relevance of dual-energy X-ray absorptiometry (DXA) as a simultaneous evaluation of fatty liver disease and atherosclerosis in patients with type 2 diabetes. Cardiovasc Diabetol. 2016;15(1):64.

37. Hsing JC, Nguyen MH, Yang B, Min Y, Han SS, Pung E, Winter SJ, Zhao X, Gan D, Hsing AW, Zhu S. Associations between body fat, muscle mass, and nonalcoholic fatty liver disease: a population-based study. Hepatol Commun. 2019;3(8):1061-72.

38. Angulo P, Hui JM, Marchesini G, Bugianesi E, George J, Farrell GC, Enders F, Saksena S, Burt AD, Bida JP, Lindor K. The NAFLD fibrosis score: a noninvasive system that identifies liver fibrosis in patients with NAFLD. Hepatology. 2007;45(4): 846-54.

39. Sterling RK, Lissen E, Clumeck N, Sola R, Correa MC, Montaner J, Sulkowski M, Torriani FJ, Dieterich DT, Thomas DL, Messinger D. Development of a simple noninvasive index to predict significant fibrosis in patients with $\mathrm{HIV} / \mathrm{HCV}$ coinfection. Hepatology. 2006;43(6):1317-25.

40. Banini BA, Sanyal AJ. Nonalcoholic fatty liver disease: epidemiology, pathogenesis, natural history, diagnosis, and current treatment options. Clin Med Insights Ther. 2016;8:CMT-S18885.

41. Salgado AL, Carvalho LD, Oliveira AC, Santos VN, Vieira JG, Parise ER. Insulin resistance index (HOMA-IR) in the differentiation of patients with non-alcoholic fatty liver disease and healthy individuals. Arq Gastroenterol. 2010;47(2):165-9.

42. Lee YH, Kim JH, Kim SR, Jin HY, Rhee EJ, Cho YM, Lee BW. Lobeglitazone, a novel thiazolidinedione, improves non-alcoholic fatty liver disease in type 2 diabetes: its efficacy and predictive factors related to responsiveness. J Korean Med Sci. 2017;32(1):60-9.

43. Shimizu M, Suzuki K, Kato K, Jojima T, Iijima T, Murohisa T, Iijima M, Takekawa H, Usui I, Hiraishi $\mathrm{H}$, Aso Y. Evaluation of the effects of dapagliflozin, a sodium-glucose co-transporter- 2 inhibitor, on hepatic steatosis and fibrosis using transient elastography in patients with type 2 diabetes and nonalcoholic fatty liver disease. Diabetes Obes Metab. 2019;21(2):285-92.
44. Komiya C, Tsuchiya K, Shiba K, Miyachi Y, Furuke S, Shimazu N, Yamaguchi S, Kanno K, Ogawa Y. Ipragliflozin improves hepatic steatosis in obese mice and liver dysfunction in type 2 diabetic patients irrespective of body weight reduction. PLoS ONE. 2016;11(3):e0151511.

45. Grgurevic I, Podrug K, Mikolasevic I, Kukla M, Madir A, Tsochatzis EA. Natural history of nonalcoholic fatty liver disease: implications for clinical practice and an individualized approach. Can J Gastroenterol Hepatol. 2020;21:2020.

46. Velasco JV, García-Jiménez ES, García-Zermeño KR, Morel-Cerda EC, Aldana-Ledesma JM, Castro-Narro GE, Cerpa-Cruz S, Tapia-Calderón DK, MercadoJauregui LA, Contreras-Omaña R. Complicaciones extrahepáticas de la enfermedad por hígado graso no alcohólico: impacto más allá del hígado. Revista de Gastroenterología de México. 2019;84(4): $472-81$.

47. Khan RS, Newsome PN. Fat and Fibrosis: Does Empagliflozin Impair the Progression of Nonalcoholic Steatohepatitis in Patients with Type 2 Diabetes Mellitus? Dig Dis Sci. 2020;65:342-4.

48. Lai LL, Vethakkan SR, Mustapha NR, Mahadeva S, Chan WK. Empagliflozin for the treatment of nonalcoholic steatohepatitis in patients with type 2 diabetes mellitus. Dig Dis Sci. 2020;65(2):623-31.

49. Kuchay MS, Krishan S, Mishra SK, Farooqui KJ, Singh MK, Wasir JS, Bansal B, et al. Effect of empagliflozin on liver fat in patients with type 2 diabetes and nonalcoholic fatty liver disease: a randomized controlled trial (E-LIIFT trial). Diabetes Care. 2018;41(8):1801-08.

50. Kusunoki M, Natsume Y, Miyata T, Tsutsumi K, Oshida Y. Effects of concomitant administration of a dipeptidyl peptidase- 4 inhibitor in Japanese patients with type 2 diabetes showing relatively good glycemic control under treatment with a sodium glucose co-transporter 2 inhibitor. Drug Res. 2018;68(12):704-9.

51. Kusunoki M, Natsume Y, Sato D, Tsutsui H, Miyata T, Tsutsumi K, Suga T, Oshida Y. Luseogliflozin, a sodium glucose co-transporter 2 inhibitor, alleviates hepatic impairment in Japanese patients with type 2 diabetes. Drug Res. 2016;66(11):603-6.

52. Shibuya T, Fushimi N, Kawai M, Yoshida Y, Hachiya H, Ito S, Kawai H, Ohashi N, Mori A. Luseogliflozin improves liver fat deposition compared to metformin in type 2 diabetes patients with non-alcoholic fatty liver disease: a prospective randomized controlled pilot study. Diabetes Obes Metab. 2018;20(2):438-42. 
53. Huwart L, Sempoux C, Vicaut E, Salameh N, Annet L, Danse E, Peeters F, ter Beek LC, Rahier J, Sinkus R, Horsmans Y. Magnetic resonance elastography for the noninvasive staging of liver fibrosis. Gastroenterology. 2008;135(1):32-40.

54. Takase T, Nakamura A, Miyoshi H, Yamamoto C, Atsumi T. Amelioration of fatty liver index in patients with type 2 diabetes on ipragliflozin: an association with glucose-lowering effects. Endocr J. 2017;64(3):363-7.

55. Seko Y, Sumida Y, Sasaki K, Itoh Y, Iijima $H$, Hashimoto T, Ishii S, Inagaki N. Effects of canagliflozin, an SGLT2 inhibitor, on hepatic function in Japanese patients with type 2 diabetes mellitus: pooled and subgroup analyses of clinical trials. J Gastroenterol. 2018;53(1):140-51.

56. Sanyal AJ, Chalasani N, Kowdley KV, McCullough A, Diehl AM, Bass NM, Neuschwander-Tetri BA, Lavine JE, Tonascia J, Unalp A, Van Natta M. Pioglitazone, vitamin E, or placebo for nonalcoholic steatohepatitis. N Engl J Med. 2010;362(18): 1675-85.

57. Roulot D, Roudot-Thoraval F, Nkontchou G, Kouacou N, Costes JL, Elourimi G, Le Clesiau H, Ziol M, Beaugrand M. Concomitant screening for liver fibrosis and steatosis in French type 2 diabetic patients using Fibroscan. Liver Int. 2017;37(12): 1897-906.

58. Shao SC, Kuo LT, Chien RN, Hung MJ, Lai EC. SGLT2 inhibitors in patients with type 2 diabetes with non-alcoholic fatty liver diseases: an umbrella review of systematic reviews. BMJ Open Diabetes Res Care. 2020;8(2):e001956.

59. Taheri H, Malek M, Ismail-Beigi F, Zamani F, Sohrabi M, Khamseh ME. Effect of empagliflozin on liver steatosis and fibrosis in patients with non-alcoholic fatty liver disease without diabetes: a randomized, double-blind, placebo-controlled trial. Adv Ther. 2020;37(11):4697-708.

60. Yki-Järvinen $H$. Thiazolidinediones and the liver in humans. Curr Opin Lipidol. 2009;20(6):477-83.

61. Polyzos SA, Kountouras J, Zavos C, Tsiaousi E. The role of adiponectin in the pathogenesis and treatment of non-alcoholic fatty liver disease. Diabetes Obes Metab. 2010;12(5):365-83.

62. Farrell GC, Larter CZ. Nonalcoholic fatty liver disease: from steatosis to cirrhosis. Hepatology. 2006;43(S1):S99-112.

63. Fujii $H$, Imajo $K$, Yoneda $M$, Nakahara $T$, Hyogo $H$, Takahashi H, Hara T, Tanaka S, Sumida Y, Eguchi Y, Chayama K. HOMA-IR: an independent predictor of advanced liver fibrosis in nondiabetic non- alcoholic fatty liver disease. J Gastroenterol Hepatol. 2019;34(8):1390-5.

64. Ting YW, Wong SW, Anuar Zaini A, Mohamed R, Jalaludin MY. Metabolic syndrome is associated with advanced liver fibrosis among pediatric patients with non-alcoholic fatty liver disease. Front Pediatr. 2019;7:491.

65. Watt GP, Lee M, Pan JJ, Fallon M, McCormick JB, Fisher-Hoch SP. Increased hemoglobin A1c correlates with increased liver stiffness in a Mexican-American population. Diabetes. 2018; 67(S1). https://doi.org/10.2337/db18-2391-PUB

66. Tanaka K, Takahashi H, Hyogo H, Ono M, Oza N, Kitajima Y, Kawanaka M, Chayama K, Saibara T, Anzai K, Eguchi Y. Epidemiological survey of hemoglobin A1c and liver fibrosis in a general population with non-alcoholic fatty liver disease. Hepatol Res. 2019;49(3):296-303.

67. You SC, Kim KJ, Kim SU, Kim BK, Park JY, Kim DY, Ahn SH, Lee WJ, Han KH. Factors associated with significant liver fibrosis assessed using transient elastography in general population. World J Gastroenterol WJG. 2015;21(4):1158.

68. Xu L, Nagata N, Nagashimada M, Zhuge F, Ni Y, Chen G, Mayoux E, Kaneko S, Ota T. SGLT2 inhibition by empagliflozin promotes fat utilization and browning and attenuates inflammation and insulin resistance by polarizing 2 macrophages in diet-induced obese mice. EBioMedicine. 2017;1(20): 137-49.

69. Hawley SA, Ford RJ, Smith BK, Gowans GJ, Mancini SJ, Pitt RD, Day EA, Salt IP, Steinberg GR, Hardie DG. The $\mathrm{Na}+$ /glucose cotransporter inhibitor canagliflozin activates AMPK by inhibiting mitochondrial function and increasing cellular AMP levels. Diabetes. 2016;65(9):2784-94.

70. Kurinami N, Sugiyama S, Yoshida A, Hieshima K, Miyamoto F, Kajiwara K, Jinnouch K, Jinnouchi T, Jinnouchi H. Dapagliflozin significantly reduced liver fat accumulation associated with a decrease in abdominal subcutaneous fat in patients with inadequately controlled type 2 diabetes mellitus. Diabetes Res Clin Pract. 2018;1(142):254-63.

71. Katsuyama H, Hakoshima M, Iijima T, Adachi $H$, Yanai H. Effects of sodium-glucose cotransporter 2 inhibitors on hepatic fibrosis in patients with type 2 diabetes: a chart-based analysis. J Endocrinol Metab. 2020;10(1):1-7.

72. Ohki T, Isogawa A, Iwamoto M, Ohsugi M, Yoshida H, Toda N, Tagawa K, Omata M, Koike K. The effectiveness of liraglutide in nonalcoholic fatty liver disease patients with type 2 diabetes mellitus 
compared to sitagliptin and pioglitazone. Sci World J. 2012;13(2012):496453.

73. Arase Y, Shiraishi K, Anzai K, Sato H, Teramura E, Tsuruya K, Hirose S, Deguchi R, Toyoda M, Mine T, Kagawa T. Effect of sodium glucose co-transporter 2 inhibitors on liver fat mass and body composition in patients with nonalcoholic fatty liver disease and type 2 diabetes mellitus. Clin Drug Investig. 2019;39(7):631-41.

74. Neeland IJ, McGuire DK, Chilton R, Crowe S, Lund SS, Woerle HJ, Broedl UC, Johansen OE. Empagliflozin reduces body weight and indices of adipose distribution in patients with type 2 diabetes mellitus. Diabetes Vasc Dis Res. 2016;13(2):119-26.

75. Ribola FA, Cancado FB, Schoueri JH, De Toni VF, Medeiros VH, Feder D. Effects of SGLT2 inhibitors on weight loss in patients with type 2 diabetes mellitus. Eur Rev Med Pharmacol Sci. 2017;21(1): 199-211.

76. Hirose H, Kawai T, Yamamoto $Y$, Taniyama M, Tomita M, Matsubara K, Okazaki Y, Ishii T, Oguma Y, Takei I, Saruta T. Effects of pioglitazone on metabolic parameters, body fat distribution, and serum adiponectin levels in Japanese male patients with type 2 diabetes. Metab Clin Exp. 2002;51(3): 314-7.

77. Prashant M, Mathur SK, Poonam P, Radhika V, Mukul M. Effect of pioglitazone on body composition in Asian Indian diabetics suggest role of limb fat in their high insulin resistance. British Journal of Medicine and Medical Research. 2016;11(4).
78. Ohta A, Kato H, Ishii S, Sasaki Y, Nakamura Y, Nakagawa T, Nagai Y, Tanaka Y. Ipragliflozin, a sodium glucose co-transporter 2 inhibitor, reduces intrahepatic lipid content and abdominal visceral fat volume in patients with type 2 diabetes. Expert Opin Pharmacother. 2017;18(14):1433-8.

79. Seino $\mathrm{Y}$, Yabe D, Sasaki T, Fukatsu A, Imazeki H, Ochiai H, Sakai S. Sodium-glucose cotransporter-2 inhibitor luseogliflozin added to glucagon-like peptide 1 receptor agonist liraglutide improves glycemic control with bodyweight and fat mass reductions in Japanese patients with type 2 diabetes: a 52-week, open-label, single-arm study. J Diabetes Investig. 2018;9(2):332-40.

80. Sasaki T, Sugawara M, Fukuda M. Sodium-glucose cotransporter 2 inhibitor-induced changes in body composition and simultaneous changes in metabolic profile: 52-week prospective LIGHT (Luseogliflozin: the Components of Weight Loss in Japanese Patients with Type 2 Diabetes Mellitus) Study. J Diabetes Investig. 2019;10(1):108-17.

81. Blonde L, Stenlöf K, Fung A, Xie J, Canovatchel W, Meininger G. Effects of canagliflozin on body weight and body composition in patients with type 2 diabetes over 104 weeks. Postgrad Med. 2016;128(4):371-80.

82. Miyake T, Yoshida S, Furukawa S, Sakai T, Tada F, Senba H, Yamamoto S, Koizumi Y, Yoshida O, Hirooka M, Kumagi T. Ipragliflozin ameliorates liver damage in non-alcoholic fatty liver disease. Open Med. 2018;13(1):402-9. 